\title{
The Gonzo lecture: Counterculture in the classroom
}

\author{
Charles Bladen
}

Business School

\begin{abstract}
This paper argues that certain university teachers consciously struggle against authoritarian oppression in their jobs and that the emergence of a countercultural teaching communication, in the form of a 'gonzo' style, is one inevitable development. The author proposes 'The Gonzo Lecture' in the light of this style's reported origins, etymology, development and diverse, present-day expressions. Suggestions are made for its potential research and operationalisation.
\end{abstract}

\section{Introduction}

Gonzo journalism was conceived by Hunter S. Thompson and its style was subsequently developed into a form of counter-culture by him and his companion, Oscar Zeta Acosta. Since then, gonzo has emerged as a style of creative expression in many diverse media. However, though the university lecture would seem highly suitable for the adaptation of this style, there has been no clear academic construct yet proposed. To further complicate this task, various adaptations called 'gonzo', which often promote aspects of counter-culture, do not otherwise clearly resemble this form of new journalism's characteristics and objectives.

The aim of this paper is to propose the elements of a gonzo style of education in the context of the supporting theoretical literature. In order that a gonzo style as applied to education might be measured and evaluated, it is proposed that it is first clearly defined, with reference to its likely origins, literary style and philosophy. Its proposed application as a communication style and a tool of critical pedagogy can then be outlined. This also requires the demystification of some of the main misconceptions of the style in the light of recent, supporting literature.

\section{Origins and definition of gonzo}

Hirst (2004) observed that though the first use of the term 'gonzo' is clear, its origin and precise meaning is not. Bill Cardoso first used the term to describe Hunter S. Thompson's style of journalism. Though Hirst cited Filatreau's (1975) rather obvious definition that gonzo simply referred to the journalistic style of Hunter S. Thompson, he also added that 'gonzo' was a term used among the Boston Irish to describe the last man standing after a drinking session. The author finally concurs with Thorne's suggestion that:

'The word itself is an adjective meaning crazy or extremist and derives from a Hipster expression made up of 'gone' (as in ecstatic, uncontrolled) and an '-o' suffix (with the 'z' for ease of 
pronunciation), or directly from the Italian gonzo, meaning a buffoon or simpleton (Thorne, 1994, pp. 97-98; cited by Hirst, 2004, p. 6).'

Thompson's first reference to gonzo was related to his Chicano lawyer, modelled on his real-life companion Oscar Zeta-Acosta, Dr. Gonzo in Fear and Loathing in Las Vegas (1972). The term 'gonzo' according to Carroll (1993; cited in Hirst, 2004) was first found in a letter by journalist Bill Cardoso as the first, formal recognition of Thompson's journalistic style, which used the first person narrative to convey factual information, and included the writer as the central actor in the piece. The result was a style of writing which could not be clearly categorised as either fiction or non fiction, but like new journalism in general, was more engaging for the reader than the objective, third- person perspective found in traditional media. This was developed over time by Thompson and also Acosta to incorporate other features also considered uncommon in the journalism of the time, which included profanity, humour, exaggeration and embellishments of the facts. Whilst Thompson's gonzo style was fuelled throughout by drug and alcohol use and abuse, Acosta's approach in Autobiography of a Brown Buffalo (1972) and The Revolt of the Cockroach People (1989), was characterised more by a rebellion against conformity to what he perceived to be an unjust political and social system. In both cases, gonzo journalism was a chaotic counter to a perceived hegemony which had resulted from a corruption of the American dream (Jiron-King, 2008).

\section{Development of the gonzo style}

Since its conception, the gonzo style has been adopted in a variety of different applications which include fiction (e.g. Acosta, 1972; 1989), marketing (Locke, 2001), sport (e.g. Merrifield, 1991), pornography (Weasels, 2008), documentary (e.g. Moore, 2002) and even theology (e.g. Goldstein, 2006). 'Gonzo pornography' according to Hirst (2004) has become the largest-selling segment of the adult entertainment industry. Despite the sub-genre's clear popularity to related fields such as marketing (Locke, 2001), there has been no specific reference made to the application of the gonzo style to education.

\section{General characteristics of the gonzo style}

Students of the gonzo journalism style generally concur that it is enigmatic, poetic, raw, and unedited. As an extreme version of new journalism style, it is journalism that can be read like a novel. Hirst (2004) used the following quote to sum up the written style:

'Gonzo can only be defined as what Hunter Thompson does...It generally consists of the fusion of reality and stark fantasy in a way that amuses the author and outrages his audience. It is point of view run wild.' (Filiatreau, 1975, cited by McKeen).

Wolfe suggested that the style came into being mainly as a product of panic, due to Thompson's renowned tendency for meeting deadlines last minute, leading often to his hurriedly compiled manuscripts being sent to his editor too late for proper review and rewriting to be effectively performed. The gonzo style is foremost recognised as being funny and popular. Thompson's writings were idiosyncratically subjective, engaging, crazy and extremist, focusing on the feelings of the writer, rather than the facts of the incident being reported. The incidents portrayed were described by Hirst as the 'legendary rendering of key moments,' (Hirst, 2004) with sharp insights and bizarre subject matter which incorporated sex and violence and satirical, wild, dark humour. 
In addition to the recognition he received for his more popular, 'non-fiction' works, Thompson was also known as an outlaw journalist who, as an unconventional, confrontational hell-raiser with an addiction to danger, pursued a thrill-seeking, death-defying legacy against a corrupt system. In his best known works such as Fear and Loathing in Las Vegas (1972) the personal and involved accounts of the 'fictionalised' accounts of incidents that reportedly happened, were used to create a counter-culture, which was designed to overthrow not only the oppressive, established culture, but also the counter-culture initially brought in to replace it. Jiron-King also recognises that Thompson with Acosta claimed that the initial counter-culture had developed its own form of corruption and their writings were a protest against this.

\section{The application of the gonzo style to university education}

There are various lines of educational enquiry related to education communication that include the use of humour, first person narrative, storytelling, language as well as the general concept of the teacher as performer. Whilst these elements certainly apply to the gonzo university lecture, there has not yet been a clear investigation into the use of the gonzo style in an educational context. This is therefore worthy of such investigation in an attempt to answer a number of key research questions, which shall be proposed later as part of this discussion.

In the light of this review of gonzo, it would be a shallow interpretation to consider the aim of the gonzo lecture to be a merely a humorous and entertaining educational presentation, or to 'beef-up' boring delivery. It would also be an error to suggest that Thompson and Acosta merely meant to promote drug and alcohol use as a method of escape from a corrupted society. Educators such as Leary (1999), though not associated with gonzo, have promoted drugs' culture to their professional detriment.

\section{The gonzo style as a tool of critical pedagogy}

The fight against 'hegemony' the dominance of one social group over others is well documented (Gramsci, 1957; 1973). Such writings maintain that a dominant class asserts its beliefs over those of others, who accept them as common sense, in return for certain benefits from the ruling class. Thus the compliance of those being ruled is essential to the relationship. Hegemony continues through ongoing struggle due to the 'common sense' of the masses being in constant flux, preventing eventual revolution by the oppressed against the oppressors. The oppressed class, subject to this social conditioning, are incapable of realising their oppression.

Government funding of British universities continues to emphasise student recruitment and course completion as a basis for awards rather than student attendance. Financial and social pressures continue to weigh heavily on students' time, availability and motivation to engage with educational processes. Educators are continually seeking new ways to engage students with subject knowledge and classroom activities. A common complaint by many academics has been that institutions recruit too many students/customers to programmes that are under resourced. To many, the resulting emphasis on quality standards, league tables and methods which have been more common in product manufacturing and consumer service industries, such as benchmarking and service blueprinting, have detracted from teachers' focus on the profession of learning and teaching. 
Additionally, complaints are also made regarding inadequate student engagement, lack of basic study skills and lower attendance rates.

However, students are often found to be increasingly experienced in media-awareness and consumerism, demanding greater levels of sophistication from the designed, lecture experience. Often, outdated content and an unsophisticated delivery style by lecturers, has resulted in students evaluating their overall educational experience negatively, or avoiding much of it altogether. However, often students identify with popular gonzo role models, such as the controversial television chef Gordon Ramsay, the business tycoon Alan Sugar, the cult entertainment 'guru' Simon Cowell and crazy science shows, such as Brainiac or those involving stunt performers such as 'Jackass'.

\section{Gonzo education as experience immersion}

Whilst traditional lectures involve mainly the transfer of knowledge, gonzo lectures mainly involve the transfer of experiences. This is particularly true of vocational degrees, which rely on sharing the lecturer's industrial practice as much as they do on the related underpinning theories. The gonzo lecturer as performer uses a variety of techniques to support their oratory. Whilst theoretical content is the focal point, the lecturer is constantly a part of each experiential account. An attempt is made throughout to take widely-accepted, academic underpinning theory and the actual facts of a true industry experience and embellish them with humour and exaggeration in order to convert them into an engaging experience. This is performed using personal narrative combined with a storytelling style.

\section{Conclusion}

Hunter S. Thompson once said, "when it stops being fun, then it's just wrong". However, it would be a mistake to characterise gonzo simply as funny, rather than an artistic, education, communication technique, belonging to a counterculture intended to liberate teachers from the confines of oppressive, institutional hegemony and students from a dry, often un-engaging educational communication style. A future research focus is required in order to deconstruct the gonzo experience in education, with a view to its operationalisation as a more effective teaching communication style used to promote learner engagement.

\section{References}

Acosta, O.Z. (1972) The Autobiography of a Brown Buffalo. New York: Vintage.

Acosta, O.Z. (1989) The Revolt of the Cockroach People. New York: Vintage.

Gramsci, A. (1957) The Modern Prince and Other Writings. Edited and translated by Louis Marks, New York: Cameron Associates, Inc.

Gramsci, A. (1973) Letters from Prison. Edited and Translated by Lynne Lawner, New York: Harper and Row.

Goldstein, N. (2006) Gonzo Judaism: A Bold Path for Renewing an Ancient Faith. St Martin's Press.

Hirst, M. (2004) What Is Gonzo? The Etymology of an Urban Legend. University of Queensland, 19 January 2004, (retrieved 1 December 2007). 
Jiron-King, S. (2008) Thompson's and Acosta's Collaborative Creation of the Gonzo Narrative Style. Comparative Literature and Culture, 10(1), March.

Leary, T. (1999) Turn On, Tune In, Drop Out (6th edition). USA: Ronin.

Locke, C. (2001) Gonzo Marketing: Winning Through Worst Practices. UK: Basic Books.

Merrifield, M. (1991) Colorado Gonzo Rides: A Mountain Bikers Guide to Colorado's Best Single Track Trails. Blue Clover Press.

Moore, M. (2002) Bowling for Columbine. Documentary. Alliance Atlantis Communications.

Thompson, H.S. (1972) Fear and Loathing in Las Vegas. UK: Palladin

Weasels, P. 'The Quick and Dirty Guide to Gonzo', www.gamelink.com (accessed 15 September 2008) 